\title{
Does previous abdominal surgery adversely affect perioperative and oncologic outcomes of laparoscopic radical cystectomy?
}

Xiaosong Wei ${ }^{1,2 \dagger}$, Jinjin $\mathrm{Lu}^{1 \dagger}$, Khurram Mutahir Siddiqui ${ }^{3}$, Fan $\mathrm{Li}^{1 *}$, Qianyuan Zhuang ${ }^{1}$, Weimin Yang ${ }^{1}$, Zhiquan $\mathrm{Hu}^{1}$, Zhong Chen ${ }^{1}$, Xiaodong Song ${ }^{1}$, Shaogang Wang ${ }^{1}$ and Zhangqun Ye ${ }^{1}$

\begin{abstract}
Background: Laparoscopic radical cystectomy (LRC) has been shown to have less estimated blood loss (EBL), transfusion rate, narcotic analgesic requirement, earlier return of bowel function, and shorter hospital stay. The aim of this study was to investigate the feasibility, peri-operative and oncologic outcomes of laparoscopic radical cystectomy (LRC) in patients with previous abdominal surgery (PAS).

Methods: We retrospectively reviewed 243 patients undergoing open radical cystectomy (ORC) or LRC with bilateral pelvic lymph node dissection and urinary diversion or cutaneous ureterostomy at a single center from January 2010 to December 2015. Demographic parameters, intra-operative variables, peri-operative records, pathologic outcomes, and complication rate were reviewed to assess the impact of PAS on peri-operative and oncologic outcomes.

Results: Patients in both ORC and LRC subgroups were homogeneous in terms of demography characteristics including age, gender, BMl, ASA score, and comorbidity. Estimated blood loss (EBL) was higher in patients with PAS undergoing ORC compared to those with no PAS $(P=0.008)$. However, there was no significant difference of EBL among patients undergoing LRC with or without PAS $(P=0.896)$. There was no statistical difference in peri-operative parameters and pathological outcomes. Patients with PAS undergoing ORC and ileal conduit had a higher vascular injury rate $(P=0$. 017). Comparing patients with PAS performed by LRC and ORC, the number of patients with the vascular injury was higher in ORC groups regardless of the type of diversion (ileal conduit, $P=0.001$, cutaneous ureterostomy, $P=0.025$ ). There is no significant difference in other complications.

Conclusion: The presence of adhesions from PAS is not a contraindication to LRC. Patients with PAS may benefit from LRC with lower estimated blood loss, fewer transfusion rates, and vascular injuries. Furthermore, the overall oncologic outcomes and complication rate are similar between LRC and ORC patients with PAS.
\end{abstract}

Keywords: Bladder cancer, Radical cystectomy, Laparoscopic surgery, Previous abdominal surgery, Perioperative, Oncologic outcomes

\footnotetext{
* Correspondence: fanli117@hotmail.com

${ }^{\dagger}$ Equal contributors

'Department of Urology, Tongji Hospital, Tongji Medical College, Huazhong

University of Science and Technology, No. 1095 Jiefang Ave, Wuhan 430030,

Hubei, People's Republic of China

Full list of author information is available at the end of the article
} 


\section{Background}

Bladder cancer is the ninth most common cancer in the world. It was estimated that 20.1 per 100,000 new patients would be diagnosed with bladder cancer, and there would be 4.4 per 100.000 projected deaths from this disease annually [1]. Radical cystectomy (RC) provides excellent local control and long-term survival, for those with high-risk non-muscle invasive bladder cancer (NMIBC), such as T1G3 or muscle-invasive bladder cancer (MIBC). Laparoscopic-assisted surgery is a minimally invasive option to promote early recovery and reduce hospital stay with comparable mortality and morbidity. The overall high complication rate from open radical cystectomy (ORC) has compelled numbers of urologists to evaluate the technical feasibility and oncologic effectiveness of LRC [2-4]. Laparoscopic radical cystectomy (LRC) has been shown to have significantly less estimated blood loss (EBL), transfusion rate, narcotic analgesic requirement, earlier return of bowel function, and shorter hospital stay.

A number of individuals undergoing radical cystectomy have a history of previous abdominal surgical (PAS). To the best of our knowledge, adhesions have been reported in up to $95 \%$ cases after abdominal surgeries. PAS is usually considered to be a surgical challenge and many urologists tend to offer open surgery to these patients due to the fear that LRC may adversely affect the outcomes $[2,3,5,6]$. Thus, PAS is considered as a relative contraindication for LRC. Studies with small numbers have documented the feasibility of LRC in patients with PAS [5, 7]. Proponents of LRC have shown that presence of adhesions is not a contraindication to LRC, and the overall complication rate and oncologic outcomes were similar between open and laparoscopic assisted groups [8-11]. While LRC has been criticized due to longer operative time and potential of higher risk for intra- and post-operative complications [5, 12], we interrogated the impact of ORC and LRC on intra-/postoperative and oncologic outcomes in bladder cancer patients with PAS.

\section{Methods}

A retrospective chart review was performed for 243 patients undergoing radical cystectomy for MIBC or highrisk NMIBC urothelial carcinoma at the Department of Urology Tongji Hospital (China) from January 2010 to December 2015. Clinical data were split into two categories: radical cystectomy with the urinary diversion of the ileal conduit or cutaneous ureterostomy. Each category was further sub-divided into two subgroups with the open or laparoscopic procedure. The demographic parameters, peri-operative, pathological and oncologic outcomes, and intra-/post-operative complications were compared. PAS was defined as any surgical procedure that is potentially known to cause abdominal or pelvic adhesions. Patients who received neo-adjuvant chemotherapy were excluded for limited in quantity. This study was approved by the ethical board of Tongji Hospital (IRB ID: TJ-C20141219). All procedures performed are in accordance with the ethical principles of Declaration of Helsinki.

\section{Surgical procedure}

The night before surgery, all RC patients were administered to bowel preparation with $50 \%$ magnesium sulfate and soapsuds enema. $1 \mathrm{~h}$ before surgery starting, patients sequentially accepted intravenous cefperazonesulbactam $1.0 \mathrm{~g}$ and metronidazole $1.0 \mathrm{~g}$ for antibiotics prophylaxis.

The standard bilateral pelvic lymph node dissection (PLND) was performed in all patients to the same extent [13]. Open radical cystectomy (ORC) with ileal conduit (IC) or cutaneous ureterostomy $(\mathrm{CU})$ was performed according to the conventional procedure $[13,14]$. Laparoscopic radical cystectomy was performed by using the five ports technique described by Huang et al. [15].

Ileal conduit diversion was performed extracorporeally through a $6 \mathrm{~cm}$ supraumbilical midline incision in the LRC group. Laparoscopic cutaneous ureterostomy was performed as follows. The distal maneuverable part of ureter was mobilized from retroperitoneal space from an incision on the peritoneum. Then the bilateral ureters were grasped and pulled to the abdominal wall through the $10 \mathrm{~mm}$ trocar port on the right side of the lateral margin of the abdominal rectus. Pneumoperitoneum was deflated to minimize the distance to the abdominal wall. The stoma was then matured. All patients were placed on a standardized post radical cystectomy care plan.

\section{Outcomes measured}

The demographic parameter records include age, gender, body mass index (BMI), surgery history, comorbidities, American Society of Anesthesiologists (ASA) scores, and primary/recurrence cancer. Operative variables included operative time, estimated blood loss (EBL), transfusion requirement of red blood cell, and fresh frozen plasma. EBL on the anesthesia note was estimated by anesthetists and was defined as the blood loss in aspirator and on the surgical gauze and sponge. Washing liquid had been excluded from the total volume by anesthetists after the surgical procedure. Peri-operative outcomes studied were compared in hemoglobin, time to return of liquid diet intake, time to drainage tube removal, and length of hospital stay. The clinical stage and pathological grade were recorded according to the TNM classification and the World Health Organization (WHO) system in 2004, respectively. Oncologic outcomes were assessed with surgical margin status and lymph node dissection numbers (LNDs). Intraoperative complications including vascular or bowel 
injury, and post-operative complications, systemic inflammatory response syndrome (SIRS), wound infection, wound dehiscence, prolonged ileus, intestinal anastomotic leakage, urinary anastomotic leakage, and deep venous thrombosis (DVT). All post-operative complications were also graded according to the Clavien-Dindo classification system in the first 90 days post-operatively.

\section{Statistical analysis}

Differences in variables with a continuous normal distribution were analyzed by using the Student's $t$ test, while variables with continuous non-normal distribution were analyzed by non-parametric Mann-Whitney $U$ test. Statistical analyses for categorical variables were performed using Pearson chi-square test or Fisher's exact test. The logistic regression model was applied to correlate the real impact of various clinical and pathological variables' affects on clinical and pathological outcomes. Statistical analysis was performed with SPSS 19.0 statistical software (IBM Inc., Armonk, NY, USA). All reported $P$ values were statistical significance at $P<0.05$.

\section{Results}

\section{Demography}

Radical cystectomy (RC) with ileal conduit (IC) diversion was performed in 132 patients, included 69 patients with ORC and 63 patients with LRC. One hundred and eleven patients underwent $\mathrm{RC}$ with cutaneous ureterostomy, including 73 patients with ORC and 38 patients with LRC. The demographic characteristics including age, gender, BMI, ASA score and comorbidity were comparable with no statistically significant difference as shown in Tables 1 and 2. However, in ORC groups, the number of patients with recurrence bladder cancer was higher in PAS group (ileal conduit, $P=0.042$; ureterostomy, $P=0.020$, respectively), but this difference was not significant in LRC groups (ileal conduit, $P=0.201$, ureterostomy, $P=0.282$, respectively). For patients undergoing $\mathrm{RC}$ with ureterostomy, the number of recurrence bladder cancer patients with PAS in ORC group was higher than LRC group $(P=0.043)$.

\section{Peri-operative outcomes}

For patients undergoing $\mathrm{RC}$ with $\mathrm{IC}$, we found that the estimated blood loss and transfusion rates were higher in patients with previous abdominal surgery undergoing ORC compared to patient with $\operatorname{LRC}(P=0.002, P=$ 0.005 , respectively). We noted no statistical difference in pre-operative hemoglobin, serum albumin, operating time, time to liquid intake, drainage tube removal, and post-operative hospital stay by RC with ileal conduit intra- or inter-group comparison (Table 3). For patients undergoing $\mathrm{RC}$ with ureterostomy, we found that the estimated blood loss was also significant lesser in LRC group $(P=0.001)$, but no statistical difference has been found in transfusion rate $(P=0.214)$ (Table 4$)$.

\section{Pathologic outcomes}

The histological diagnosis of all the patients in this study was urothelial carcinoma. The average positive surgical margin (PSM) rate was 9\%. And the overall median number of lymph node (LN) yield was 10. The TNM stage and pathological grade were evenly distributed and illustrated in Tables 5 and 6, respectively.

\section{Complications}

We performed a logistic regression model to control various clinical and pathological variables, including gender, PAS, ORC or LRC, primary/recurrence, TNM staging, pathologic grade, and urinary diversion. The PAS has not been found to be an adverse variable to predict the postoperative complication $(P=0.107)$. In the same analysis, the urinary diversion approach (ileal conducts vs. cutaneous ureterostomies) was an adverse predictor to the intraoperative vascular injury $(P=0.017)$ and post-operation complication rate $(P<0.001)$. By applying Pearson chisquare tests, no significant difference between abdominal and pelvic PAS on intra-operative vascular injury $(P=$ $0.594)$ or post-operative complication $(P=0.342)$ had been noted in our analysis. ORC was also been found to be a variable to predict intra-operative complication concurrence rate. The vascular injury rate was found to be higher in patients treated by ORC $(P=0.017)$. Similarly, the vascular complication was significantly higher in patients with PAS undergoing ORC compared to LRC $(P=0.001)$. Post-operative complications were graded according to Clavien-Dindo classification system. The detailed comparison is shown in Tables 7 and 8.

\section{Discussion}

In the last two decades, with the promise of reducing peri-operative morbidity and improving oncologic and functional outcomes, laparoscopic surgery has made significant inroads in oncologic surgery including high-risk bladder cancer $[4,16]$. Decreased EBL, lesser transfusions, rapid return of bowel function, and shorter hospital stay are proven benefits $[9,11]$.

Intra-abdominal and pelvic adhesions are frequently encountered in patients with PAS. Numbers of studies have suggested that abdominal and pelvic adhesions are associated with intra-operative vascular and bowel injuries $[17,18]$. This prohibits numbers of urologists to offer laparoscopic surgery due to the fear of causing additional injuries. In the present study, $28 \%$ patients in our study have PAS history. The demographic characteristics of all our subgroups were homogenous, and history of PAS did not restrict the decision to offer open or laparoscopic surgery at our center. 
Table 1 Demography for patients with radical cystectomy and ileal conduit

\begin{tabular}{|c|c|c|c|c|c|c|c|}
\hline & ORC (69) & & & LRC (63) & & & ORC vs. LRC with PAS \\
\hline & PAS & & & PAS & & & \\
\hline & No & Yes & $P$ value & No & Yes & $P$ value & $P$ value \\
\hline Demography & 50 & 19 & & 51 & 12 & & \\
\hline Age & $58.2 \pm 9.0$ & $54.6 \pm 10.0$ & $0.156^{*}$ & $59.9 \pm 9.0$ & $61.8 \pm 9.9$ & $0.538^{*}$ & $0.061^{*}$ \\
\hline Body mass index (BMI) $\left(\mathrm{Kg} / \mathrm{m}^{2}\right)$ & $24.2 \pm 3.8$ & $26.0 \pm 4.6$ & $0.120^{*}$ & $24.6 \pm 3.9$ & $26.1 \pm 2.5$ & $0.211^{*}$ & $0.937^{*}$ \\
\hline Gender & & & $1.000^{\#}$ & & & $1.000^{\#}$ & $1.000^{\#}$ \\
\hline Male & 43 & 17 & & 45 & 11 & & \\
\hline Female & 7 & 2 & & 6 & 1 & & \\
\hline ASA score ${ }^{a}$ & 14 & & $1.000^{\#}$ & 45 & & $0.201^{\#}$ & $0.350^{\#}$ \\
\hline 1 & 1 & 1 & & 3 & 0 & & \\
\hline 2 & 6 & 2 & & 24 & 4 & & \\
\hline 3 & 3 & 1 & & 9 & 5 & & \\
\hline 4 & 0 & 0 & & & & & \\
\hline Primary/recurrence tumor & & & $0.042^{\#}$ & & & $0.282^{\#}$ & $1.000^{\#}$ \\
\hline Primary & 32 & 7 & & 30 & 5 & & \\
\hline Recurrence & 18 & 12 & & 21 & 7 & & \\
\hline
\end{tabular}

*Student's $t$ test was used for statistical analysis

\#Chi-square test was used for statistical analysis

${ }^{a}$ ASA score was started applying in anesthesiology assessment from 2013 . Only 14 cases in open and 45 cases in laparoscopic were evaluated by ASA, respectively

PAS pose two significant challenges; the first hurdle is the entry into peritoneal space. To safely proceed with the intended LRC procedures, surgeons might lysis adhesions before trocar placement. Poorly placed trocar may preclude efficient completion of the LRC, and processing around adhesions may potentially lead to visceral or vascular injury. Upon entering the peritoneal space, the adhesions require taking down to accurately identify anatomical landmarks and progress with the dissection. Our confidence in this technique is reflected by the fact that no open conversion was needed in our LRC cases.

Table 2 Demography for patients with radical cystectomy and cutaneous ureterostomy

\begin{tabular}{|c|c|c|c|c|c|c|c|}
\hline & ORC (73) & & & LRC (38) & & & ORC vs. LRC with PAS \\
\hline & $\overline{P A S}$ & & & $\overline{\text { PAS }}$ & & & \\
\hline & No & Yes & $P$ value & No & Yes & $P$ value & $P$ value \\
\hline Demography & 48 & 25 & & 27 & 11 & & \\
\hline Age & $69.7 \pm 10.5$ & $64.8 \pm 13.5$ & $0.054^{*}$ & $64.3 \pm 7.7$ & $63.4 \pm 11.8$ & $0.805^{*}$ & $0.881^{*}$ \\
\hline Body mass index (BMI) $\left(\mathrm{Kg} / \mathrm{m}^{2}\right)$ & $22.6 \pm 3.0$ & $21.5 \pm 3.3$ & $0.181^{*}$ & $23.5 \pm 3.6$ & $23.2 \pm 4.4$ & $0.826^{*}$ & $0.210^{*}$ \\
\hline Gender & & & $0.975^{\#}$ & & & $0.872^{\#}$ & $0.961^{\#}$ \\
\hline Male & 40 & 20 & & 22 & 8 & & \\
\hline Female & 8 & 5 & & 5 & 3 & & \\
\hline ASA score ${ }^{a}$ & 30 & & $0.566^{\#}$ & 29 & & $0.201^{\#}$ & $0.413^{\#}$ \\
\hline 1 & 0 & 0 & & 0 & 1 & & \\
\hline 2 & 10 & 2 & & 15 & 3 & & \\
\hline 3 & 11 & 6 & & 7 & 3 & & \\
\hline 4 & 1 & 0 & & 0 & 0 & & \\
\hline Primary/recurrence tumor & & & $0.02^{\#}$ & & & $0.538^{\#}$ & $0.043^{\#}$ \\
\hline Primary & 31 & 9 & & 15 & 9 & & \\
\hline Recurrence & 17 & 16 & & 12 & 3 & & \\
\hline
\end{tabular}

*Student's $t$ test was used for statistical analysis

${ }^{\#}$ Chi-square test was used for statistical analysis

${ }^{a}$ ASA score was started applying in anesthesiology assessment from 2013 . Only 30 cases in open and 29 cases in laparoscopic were evaluated by ASA, respectively 
Table 3 Peri-operative information for patients with radical cystectomy and ileal conduit

\begin{tabular}{|c|c|c|c|c|c|c|c|}
\hline & \multicolumn{3}{|l|}{ ORC (69) } & \multicolumn{3}{|l|}{ LRC (63) } & \multirow{3}{*}{$\begin{array}{l}\text { ORC vs. LRC with PAS } \\
P \text { value }\end{array}$} \\
\hline & \multicolumn{2}{|l|}{ PAS } & \multirow[b]{2}{*}{$P$ value } & \multicolumn{2}{|l|}{ PAS } & \multirow[b]{2}{*}{$P$ value } & \\
\hline & No & Yes & & No & Yes & & \\
\hline $\begin{array}{l}\text { Pre-operation hemoglobin } \\
\text { (HB) }(\mathrm{g} / \mathrm{L})\end{array}$ & $129.6 \pm 16.5$ & $129.1 \pm 23.1$ & $0.912^{*}$ & $129.9 \pm 16.8$ & $132.7 \pm 17.4$ & $0.606^{*}$ & $0.649^{*}$ \\
\hline $\begin{array}{l}\text { Pre-operation serum } \\
\text { albumin }(\mathrm{g} / \mathrm{L})\end{array}$ & $37.8 \pm 2.9$ & $37.8 \pm 4.5$ & $0.988^{*}$ & $38.8 \pm 3.5$ & $37.3 \pm 3.2$ & $0.173^{*}$ & $0.742^{*}$ \\
\hline Operating time (min) & $397 \pm 72$ & $417 \pm 67$ & $0.297^{*}$ & $440 \pm 79$ & $435 \pm 89$ & $0.848^{*}$ & $0.522^{*}$ \\
\hline Estimated blood loss (ml) & $1000(788,1700)$ & $1600(1200,3000)$ & $0.008^{* *}$ & $500(300,1150)$ & $550(325,900)$ & $0.896^{* *}$ & $0.002^{* *}$ \\
\hline Transfusion no. & 46 & 19 & $0.327 \#$ & 34 & 7 & $0.738 \#$ & $0.005 \#$ \\
\hline Time to liquid intake (days) & $6(5,7)$ & $6(5.75,7.25)$ & $0.799^{* *}$ & $5.5(5,6)$ & $5(4.25,5)$ & $0.176^{* *}$ & $0.096^{* *}$ \\
\hline $\begin{array}{l}\text { Time to drainage tube } \\
\text { removal (days) }\end{array}$ & $10.5(7,14)$ & $10.5(7.75,21.25)$ & $0.642^{* *}$ & $9(7,12.75)$ & $8.5(7,18.75)$ & $0.986^{* *}$ & $0.393^{* *}$ \\
\hline $\begin{array}{l}\text { Post-operation hospital } \\
\text { stay (days) }\end{array}$ & $17(13,22)$ & $21.5(14.75,29.5)$ & $0.185^{* *}$ & $14.5(13,20)$ & $15.5(13,34.25)$ & $0.358^{* *}$ & $0.340^{* *}$ \\
\hline
\end{tabular}

*Student's $t$ test was used for statistical analysis

**Mann-Whitney $U$ test was used for statistical analysis

\#Chi-square test was used for statistical analysis

Operative time, time to drainage tube removal, and length of hospital stay in patients undergoing LRC were not only comparable to our ORC cohort but also similar to other published report on LRC without previous PAS $[12,19]$. In our series, we report a lower EBL and transfusion rate in patients with PAS undergoing LRC compared to ORC subgroups. Peri-operative transfusion is an independent predictor of decreased overall survival in patients with solid organ malignancies. Based on a large cohort study, Linder et al. noted that due to the potential immunosuppressive effect of red blood cell transfusion, perioperative blood transfusion (PBT) is associated with significantly increased risks of cancer recurrence and mortality following radical cystectomy [20]. Thus, bladder cancer patients with PAS may benefit from LRC by reducing transfusion rate. Intriguingly, by applying different statistic analysis, a controversial conclusion was concluded by Morgan et al. They contributed the paradox to inadequately and inaccurately control for relevant confounding variables. Such variables included increased age, surgical complexity, adverse tumor pathology, and possibly surgical expertise [21]. The authors emphasized that elucidating the association between PBT and prognosis should provide additional statistical modeling and further scrutiny. Unfortunately, randomized, prospective, long-term survival has not been provided in our study. In our logistic regression model, the urinary diversion approach was an adverse predictor to the intra-operative and post-operation complication rate. Thus, evaluating LRC and ORC with the urinary diversion of the ileal conduit and cutaneous ureterostomy separately made us better understanding the effect of PAS on post-operative outcomes. In this study, PAS did not adversely affect the early recovery of bowel

Table 4 Peri-operative information for patients with radical cystectomy and cutaneous ureterostomy

\begin{tabular}{|c|c|c|c|c|c|c|c|}
\hline & \multicolumn{3}{|l|}{ ORC (73) } & \multicolumn{3}{|l|}{ LRC (38) } & \multirow{3}{*}{$\begin{array}{l}\text { ORC vs. LRC with PAS } \\
P \text { value }\end{array}$} \\
\hline & \multicolumn{2}{|l|}{ PAS } & \multirow[b]{2}{*}{$P$ value } & \multicolumn{2}{|l|}{ PAS } & \multirow[b]{2}{*}{$P$ value } & \\
\hline & No & Yes & & NO & Yes & & \\
\hline Pre-operation hemoglobin (HB) (g/L) & $116.9 \pm 20.3$ & $115.8 \pm 17.7$ & $0.820^{*}$ & $128.1 \pm 17.2$ & $122.4 \pm 12.9$ & $0.333^{*}$ & $0.273^{*}$ \\
\hline Pre-operation serum albumin ( $\mathrm{g} / \mathrm{L})$ & $35.1 \pm 4.3$ & $36.3 \pm 4.5$ & $0.247^{*}$ & $38.3 \pm 3.2$ & $35.9 \pm 3.1$ & $0.040^{*}$ & $0.736^{*}$ \\
\hline Operating time (min) & $240(210,308)$ & $240(210,285)$ & $0.664^{* *}$ & $285(240,360)$ & $308(236,398)$ & $0.246^{* *}$ & $0.143^{* *}$ \\
\hline Estimated blood loss (ml) & $1000(600,1850)$ & $1100(600,2000)$ & $0.964^{* *}$ & $350(200,463)$ & $450(288,775)$ & $0.163^{* *}$ & $0.001^{* *}$ \\
\hline Transfusion no. & 46 & 21 & $0.172 \#$ & 12 & 7 & $0.283 \#$ & 0.214 \\
\hline Time to liquid intake (days) & $3(3,4.25)$ & $4(3,4)$ & $0.148^{* *}$ & $3(2,5)$ & $2(2,5.5)$ & $0.751^{* *}$ & $0.751^{* *}$ \\
\hline Time to drainage tube removal (days) & $8(6.75,9.25)$ & $7(7,13)$ & $0.851^{* *}$ & $10(6.75,15)$ & $10(9,15.75)$ & $0.961^{* *}$ & $0.128^{* *}$ \\
\hline Post-operation hospital stay (days) & $13(10.75,16.25)$ & $13(11,17)$ & $0.379^{* *}$ & $14.5(11.75,18.25)$ & $14(13,18.75)$ & $0.604^{* *}$ & $0.654^{* *}$ \\
\hline
\end{tabular}

*Student's $t$ test was used for statistical analysis

**Mann-Whitney $U$ was used for statistical analysis

${ }^{\#}$ Chi-square test was used for statistical analysis 
Table 5 Pathologic parameters for patients with radical cystectomy and ileal conduit

\begin{tabular}{|c|c|c|c|c|c|c|c|}
\hline & ORC (69) & & & LRC (63) & & & ORC vs. LRC with PAS \\
\hline & PAS & & & PAS & & & \\
\hline & No & Yes & $P$ value & No & Yes & $P$ value & $P$ value \\
\hline T stage & & & $0.517^{\#}$ & & & $0.239^{\#}$ & $0.360^{\#}$ \\
\hline T1, Tis & 18 & 5 & & 23 & 7 & & \\
\hline $\mathrm{T} 2$ & 15 & 5 & & 17 & 2 & & \\
\hline T3 & 13 & 5 & & 9 & 1 & & \\
\hline T4 & 4 & 4 & & 2 & 2 & & \\
\hline N stage & & & $0.389^{\#}$ & & & $0.400^{\#}$ & $0.555^{\#}$ \\
\hline NO & 44 & 16 & & 46 & 10 & & \\
\hline N1 & 3 & 0 & & 2 & 1 & & \\
\hline N2 & 3 & 3 & & 3 & 1 & & \\
\hline N3 & 0 & 0 & & 0 & 0 & & \\
\hline Tumor grade (WHO 2004) & & & $0.446^{\#}$ & & & $0.538^{\#}$ & $0.620^{\#}$ \\
\hline Low grade & 18 & 5 & & 14 & 5 & & \\
\hline High grade & 32 & 14 & & 37 & 7 & & \\
\hline Positive surgical margin (PSM) & 4 & 2 & $1.000^{\#}$ & 2 & 1 & $1.000^{\#}$ & $1.000^{\#}$ \\
\hline Lymph node dissection (LND) & $10.6 \pm 3.9$ & $11.9 \pm 4.6$ & $0.279^{*}$ & $11.0 \pm 2.8$ & $11.9 \pm 3.9$ & $0.473^{*}$ & $0.777^{*}$ \\
\hline
\end{tabular}

${ }^{\#}$ Chi-square test was used for statistical analysis

*Student's $t$ test was used for statistical analysis

Table 6 Pathologic parameters for patients with radical cystectomy and cutaneous ureterostomy

\begin{tabular}{|c|c|c|c|c|c|c|c|}
\hline & \multicolumn{3}{|l|}{ ORC (73) } & \multicolumn{3}{|l|}{ LRC (38) } & \multirow{3}{*}{$\begin{array}{l}\text { ORC vs. LRC with PAS } \\
P \text { value }\end{array}$} \\
\hline & \multicolumn{2}{|l|}{ PAS } & \multirow[b]{2}{*}{$P$ value } & \multicolumn{2}{|l|}{ PAS } & \multirow[b]{2}{*}{$P$ value } & \\
\hline & No & Yes & & No & Yes & & \\
\hline T stage & & & $0.321^{\#}$ & & & $0.744^{\#}$ & $0.788^{\#}$ \\
\hline $\mathrm{T1}$, Tis & 11 & 8 & & 8 & 5 & & \\
\hline $\mathrm{T} 2$ & 22 & 7 & & 6 & 2 & & \\
\hline T3 & 7 & 7 & & 9 & 2 & & \\
\hline T4 & 8 & 3 & & 4 & 2 & & \\
\hline N stage & & & $0.865^{\#}$ & & & $0.469^{\#}$ & $1.000^{\#}$ \\
\hline NO & 42 & 24 & & 21 & 11 & & \\
\hline N1 & 3 & 0 & & 3 & 0 & & \\
\hline N2 & 2 & 1 & & 3 & 0 & & \\
\hline N3 & 1 & 0 & & 0 & 0 & & \\
\hline Tumor grade (WHO 2004) & & & $0.639^{\#}$ & & & $1.000^{\#}$ & $1.000^{\#}$ \\
\hline Low grade & 14 & 6 & & 6 & 2 & & \\
\hline High grade & 34 & 19 & & 21 & 9 & & \\
\hline Positive surgical margin (PSM) & 5 & 3 & $1.000^{\#}$ & 3 & 2 & $0.615^{\#}$ & $1.000^{\#}$ \\
\hline Lymph node dissection (LND) & $9.1 \pm 3.5$ & $10.4 \pm 3.6$ & $0.14^{*}$ & $10.1 \pm 2.4$ & $11.3 \pm 3.1$ & $0.253^{*}$ & $0.403^{*}$ \\
\hline
\end{tabular}

*Student's $t$ test was used for statistical analysis \#Chi-square test was used for statistical analysis 
Table 7 Complication for patients with radical cystectomy and ileal conduit

\begin{tabular}{|c|c|c|c|c|c|c|c|}
\hline & ORC & & & $\underline{L R C}$ & & & ORC vs. LRC with PAS \\
\hline & PAS & & & PAS & & & \\
\hline & No & Yes & $P$ value & No & Yes & $P$ value & $P$ value \\
\hline Clavien-Dindo classification & & & $0.191^{\#}$ & & & $0.060^{\#}$ & $0.445^{\#}$ \\
\hline I & 2 & 2 & & 2 & 1 & & \\
\hline$\|$ & 3 & 2 & & 7 & 1 & & \\
\hline Illa & 3 & 1 & & 1 & 3 & & \\
\hline IIlb & 2 & 3 & & 2 & 0 & & \\
\hline IVa & 0 & 0 & & 0 & 0 & & \\
\hline $\mathrm{IVb}$ & 0 & 0 & & 0 & 0 & & \\
\hline V & 0 & 0 & & 0 & 0 & & \\
\hline Vascular injury & 31 & 18 & $0.017^{\#}$ & 19 & 4 & $1.000^{\#}$ & $0.001^{\#}$ \\
\hline Bowel injury & 0 & 1 & $0.275^{\#}$ & 0 & 0 & - & $1.000^{\#}$ \\
\hline SIRS & 4 & 2 & $1.000^{\#}$ & 1 & 1 & $0.828^{\#}$ & $1.000^{\#}$ \\
\hline Wound infection & 5 & 5 & $0.181^{\#}$ & 5 & 4 & $0.102^{\#}$ & $0.990^{\#}$ \\
\hline Wound dehiscence (need secondary suture) & 5 & 3 & $0.803^{\#}$ & 3 & 3 & $0.138^{\#}$ & $0.868^{\#}$ \\
\hline Intestinal obstruction, ileus & 2 & 2 & $0.646^{\#}$ & 5 & 1 & $1.000^{\#}$ & $1.000^{\#}$ \\
\hline Intestinal leakage & 0 & 1 & $0.275^{\#}$ & 0 & 0 & - & $1.000^{\#}$ \\
\hline Urine leakage & 1 & 0 & $1.000^{\#}$ & 0 & 0 & - & - \\
\hline Thrombosis & 1 & 0 & $1.000^{\#}$ & 1 & 1 & $0.828^{\#}$ & $0.387^{\#}$ \\
\hline
\end{tabular}

${ }^{\#}$ Chi-square test was used for statistical analysis

Table 8 Complication for patients with radical cystectomy and cutaneous ureterostomy

\begin{tabular}{|c|c|c|c|c|c|c|c|}
\hline & \multicolumn{3}{|c|}{ ORC (73) } & \multicolumn{3}{|c|}{ LRC (38) } & \multirow{3}{*}{$\begin{array}{l}\text { ORC vs. LRC with PAS } \\
P \text { value }\end{array}$} \\
\hline & \multicolumn{2}{|l|}{ PAS } & \multirow[b]{2}{*}{$P$ value } & \multicolumn{2}{|l|}{ PAS } & \multirow[b]{2}{*}{$P$ value } & \\
\hline & $\overline{\text { No }}$ & Yes & & No & Yes & & \\
\hline Clavien-Dindo classification & & & $0.541^{\#}$ & & & $0.762^{\#}$ & $1.000^{\#}$ \\
\hline I & 1 & 0 & & 0 & 0 & & \\
\hline$\|$ & 0 & 1 & & 1 & 1 & & \\
\hline IIla & 1 & 2 & & 0 & 0 & & \\
\hline Illb & 1 & 0 & & 2 & 0 & & \\
\hline $\mathrm{IVa}$ & 0 & 0 & & 0 & 0 & & \\
\hline $\mathrm{IVb}$ & 0 & 0 & & 0 & 0 & & \\
\hline V & 1 & 0 & & 0 & 0 & & \\
\hline Vascular injury & 30 & 18 & $0.417^{\#}$ & 4 & 3 & $0.662^{\#}$ & $0.025^{\#}$ \\
\hline Bowel injury & 0 & 0 & - & 0 & 0 & - & \\
\hline SIRS & 0 & 1 & $0.342^{\#}$ & 0 & 0 & - & $1.000^{\#}$ \\
\hline Wound infection & 3 & 1 & $1.000^{\#}$ & 1 & 0 & $1.000^{\#}$ & $1.000^{\#}$ \\
\hline Wound dehiscence (need secondary suture) & 2 & 1 & $1.000^{\#}$ & 1 & 0 & $1.000^{\#}$ & $1.000^{\#}$ \\
\hline Intestinal obstruction, ileus & 0 & 2 & $0.114^{\#}$ & 1 & 1 & $1.000^{\#}$ & $1.000^{\#}$ \\
\hline Intestinal leakage & 0 & 0 & - & 0 & 0 & - & - \\
\hline Urine leakage & 0 & 0 & - & 1 & 0 & $1.000^{\#}$ & - \\
\hline Thrombosis & 0 & 1 & $0.342^{\#}$ & 0 & 0 & - & $1.000^{\#}$ \\
\hline
\end{tabular}

${ }^{\#}$ Chi-square test was used for statistical analysis 
function and return to normal activity for patients with LRC.

Post-operative hospital stay is a crude indicator of the recovery after surgery [22]. There are several biases which may affect this outcome, social norms, reimbursement models and availability of a reliable rehabilitative system are import considerations which cannot be ignored. Thus, the hospital stay may not always be considered as a parameter for post-operative recovery. The differences in the healthcare system between China and western countries have been noted before [2]. Regardless of fitness for discharge, almost all patients from subgroups in this study insisted on staying until drainage tubes and sutures were removed.

The ability of LRC to obtain the same quality of oncologic control as ORC has been questioned in several previous studies. Lymph node dissection number (LNDs) and positive surgical margin (PSM) status are two independent predictive factors for oncologic outcomes. Several studies have taken LNDs yield as an indicator of surgical quality with RC [23-25]. Previous studies documented that laparoscopic pelvic lymph node dissection may be hindered by the presence of abdominal adhesions $[24,26]$. However, regardless fewer lymph nodes retrieved from the patients with PAS, these studies also noted that the lymph node dissection may still be carried out safely and reliably [27]. Herr et al. have described 10 to 14 lymph nodes dissected as an oncologic benchmark for RC [28]. This standard has been achieved in our cohort, with a median LNDs retrieved of 10 . We acknowledge that the nodes removed in the pathological finding are under the mean of most of the series published. We attribute this issue to the factors below: (1) we regularly performed standard bilateral pelvic lymphadenectomy, but we rarely performed extended or super-extended PLND. This may significantly decrease the number of retrieved nodes, (2) during the PLND procedure, en bloc technique were preferentially performed on the patients who were possible. However, published studies had noted that more lymph nodes could be indentified in the pathological analysis by separated submission rather than en bloc submission [29]. Furthermore, we found no statistically significant difference in the node count among the two groups in general and those with or without PAS.

PSM has been reported as a significant predictor of recurrence and cancer-specific death. Zeng et al. noted that LRC achieved similar peri-operative outcomes to ORC without compromising oncologic or pathologic outcomes [2]. In our previous publication, LRC achieved an identical prognosis to ORC in terms of local recurrence and cancer-free survival [30]. In this study, for patients with PAS, LRC did not affect the positive margin rate compared to ORC. Herr et al. had described PSM rate of less than $10 \%$ as another benchmark [28]. However, some other studies had reported a PSM of less than 5\% [31]. We acknowledge that our present PSM rate of 9\% was higher than desirable. However, to our knowledge, none of the studies above had taken the pathological stage into consideration while calculating PSM rate. It should be noted that $34 \%$ patients ( 82 cases) were harboring locally advanced disease (53 had pT3 and 29 had pT4a) while none of the T1-T2 stage patients had PSM. Dotan et al. also noted that patients with organ confined disease were less likely to have PSM while tumor infiltration may be the main limitation in achieving a negative margin in locally advanced disease [32].

Several studies have demonstrated that a significantly higher frequency of complications after LRC in patients with PAS. Columbo et al. found a $48 \%$ complication rate in LRC patients, which made LRC an independent risk factor for peri-operative complications in patients with PAS [33]. Our overall complication rate was $18 \%$, and there was no Clavien grade IV complication. Furthermore, for patients with PAS or without PAS, LRC did not adversely increase the complication rate compared to ORC subgroups. Zeng et al. reported a higher complication rate in elder patients undergoing LRC [2]. Several authors have previously determined age to be a significant risk factor for RC post-operative complications. In our center, the age of patients underwent RC ranged from 34 to 88 while the average age was 62 , slightly less than other previous studies, which may explain why we have a lower post-operative complication rate. Because of higher comorbidities, senior patients should be carefully screened with stricter discretion and counseled about their risk of obstacles after surgery. Albisinni et al. reported re-operation rate of $12 \%$ in the first 30 days after LRC [24]. In our series, the reoperation rate was less than $8 \%$ patients in the first 90 days.

The limitations of the current studies include the biases associated with a retrospective study. Although a randomized, prospective study with long-term follow-up would be better to assess the effect of PAS on LRC, such a study is practically very difficult to conduct.

\section{Conclusions}

The results of this study demonstrate that the oncologic efficacy and post-operative complications and morbidity rate are similar between patients with PAS undergoing LRC or ORC. The presence of adhesions from PAS is not a contraindication to LRC. Furthermore, patients with PAS may additionally benefit from LRC, due to lesser blood loss, transfusion rate, and intra-operative vascular injury rate.

\section{Abbreviations}

ASA: American Society of Anesthesiologists; BMl: Body mass index;

CU: Cutaneous ureterostomy; DVT: Deep venous thrombosis; EBL: Estimated 
blood loss; IC: Ileal conduit; LN: Lymph node; LNDs: Lymph node dissection number; LRC: Laparoscopic radical cystectomy; MIBC: Muscle-invasive bladder cancer; NMIBC: Non-muscle invasive bladder cancer; ORC: Open radical cystectomy; PAS: Previous abdominal surgery; PLND: Pelvic lymph node dissection; PSM: Positive surgical margin; RC: Radical cystectomy; SIRS: Systemic inflammatory response syndrome; WHO: World Health Organization

\section{Acknowledgements}

Not applicable.

\section{Funding}

This project was supported by National Natural Sciences Foundation of China (no. 81302219).

\section{Availability of data and materials}

The datasets in this study are available from the corresponding author on reasonable request.

\section{Authors' contributions}

$F L, W Y$, and XS designed this study. XW and $J L$ collected the data. $F L, X S$, KMS, and QZ analyzed the data. FL and XW wrote the original draft. KMS, ZY, SW, ZH, and ZC edited the paper. All authors reviewed the results and approved the final version of the manuscript.

\section{Ethics approval and consent to participate}

The institutional review board of Tongji Hospital approved the study (IRB ID:

TJ-C20141219). This study does not involve the use of any animal data or tissue.

\section{Consent for publication}

Not applicable.

\section{Competing interests}

The authors declare that they have no competing interests.

\section{Publisher's Note}

Springer Nature remains neutral with regard to jurisdictional claims in published maps and institutional affiliations.

\section{Author details}

'Department of Urology, Tongji Hospital, Tongji Medical College, Huazhong University of Science and Technology, No. 1095 Jiefang Ave, Wuhan 430030, Hubei, People's Republic of China. ${ }^{2}$ Department of Urology, First Affiliated Hospital of Zheng Zhou University, Zhengzhou 450052, Henan, People's Republic of China. ${ }^{3}$ Departments of Surgery (Urology), Western University, London Health Sciences Centre, London, ON N6A 5W9, Canada.

Received: 21 April 2017 Accepted: 10 January 2018

Published online: 17 January 2018

\section{References}

1. Siegel R, Naishadham D, Jemal A. Cancer statistics, 2013. CA Cancer J Clin. 2013;63:11-30

2. Zeng S, Zhang Z, Yu X, Song R, Wei R, Zhao J, et al. Laparoscopic versus open radical cystectomy for elderly patients over 75-year-old: a single center comparative analysis. PLoS One. 2014;9:e98950.

3. Yasui T, Tozawa K, Ando R, Hamakawa T, Iwatsuki S, Taguchi K, et al. Laparoscopic versus open radical cystectomy for patients older than 75 years: a single-center comparative analysis. Asian Pac J Cancer Prev. 2015;16: 6353-8.

4. Parra RO, Andrus CH, Jones JP, Boullier JA. Laparoscopic cystectomy: initial report on a new treatment for the retained bladder. J Urol. 1992;148:1140-4.

5. Yuh BE, Ciccone J, Chandrasekhar R, Butt ZM, Wilding GE, Kim HL, et al. Impact of previous abdominal surgery on robot-assisted radical cystectomy. JSLS. 2009;13:398-405.

6. Pruthi RS, Wallen EM. Robotic-assisted laparoscopic radical cystoprostatectomy. Eur Urol. 2008;53:310-22.

7. Nazemi T, Galich A, Smith L, Balaji KC. Robotic urological surgery in patients with prior abdominal operations is not associated with increased complications. Int J Urol. 2006;13:248-51.
8. Pautler SE, Phillips JL, Walther MM. Assessment of risk for intra-abdominal adhesions at laparoscopy for urological tumors. J Urol. 2002;168:2391-4.

9. Khan MS, Gan C, Ahmed K, Ismail AF, Watkins J, Summers JA, et al. A singlecentre early phase randomised controlled three-arm trial of open, robotic, and laparoscopic radical cystectomy (CORAL). Eur Urol. 2016;69:613-21.

10. Haber GP, Crouzet S, Gill IS. Laparoscopic and robotic assisted radical cystectomy for bladder cancer: a critical analysis. Eur Urol. 2008;54:54-62.

11. Albisinni S, Oderda M, Fossion L, Varca V, Rassweiler J, Cathelineau X, et al. The morbidity of laparoscopic radical cystectomy: analysis of postoperative complications in a multicenter cohort by the European Association of Urology (EAU)-section of Uro-technology. World J Urol. 2016;34:149-56.

12. Haber GP, Campbell SC, Colombo JJ, Fergany AF, Aron M, Kaouk J, et al. Perioperative outcomes with laparoscopic radical cystectomy: "pure laparoscopic" and "open-assisted laparoscopic" approaches. Urology. 2007; 70:910-5.

13. Smith JA, Howards SS, Premiger GM. Hinman's atlas of urologic surgery. 3rd ed. Philadelphia: Sanders Elsevier; 2012. p.501-512, 615-628.

14. Rodriguez AR, Lockhart A, King J, Wiegand L, Carrion R, Ordorica R, et al. Cutaneous ureterostomy technique for adults and effects of ureteral stenting: an alternative to the ileal conduit. J Urol. 2011;186:1939-43.

15. Lin T, Fan X, Zhang C, Xu K, Liu H, Zhang J, et al. A prospective randomised controlled trial of laparoscopic vs open radical cystectomy for bladder cancer: perioperative and oncologic outcomes with 5-year follow-upT Lin et al. Br J Cancer. 2014;110:842-9.

16. Sogni F, Brausi M, Frea B, Martinengo C, Faggiano F, Tizzani A, et al. Morbidity and quality of life in elderly patients receiving ileal conduit or orthotopic neobladder after radical cystectomy for invasive bladder cancer. Urology. 2008: 71:919-23.

17. Seifman BD, Dunn RL, Wolf JJ. Transperitoneal laparoscopy into the previously operated abdomen: effect on operative time, length of stay and complications. J Urol. 2003;169:36-40.

18. Parsons JK, Jarrett TJ, Chow GK, Kavoussi LR. The effect of previous abdominal surgery on urological laparoscopy. J Urol. 2002;168:2387-90.

19. Guillotreau J, Game X, Mouzin M, Doumerc N, Mallet R, Sallusto F, et al. Radical cystectomy for bladder cancer: morbidity of laparoscopic versus open surgery. J Urol. 2009;181:554-9.

20. Linder BJ, Frank I, Cheville JC, Matthew KT, Thompson RH, Tarrell RF, et al. The impact of perioperative blood transfusion on cancer recurrence and survival following radical cystectomy. Eur Urol. 2013;63:839-45.

21. Morgan TM, Barocas DA, Chang SS, Phillips SE, Salem S, Clark PE, et al. The relationship between perioperative blood transfusion and overall mortality in patients undergoing radical cystectomy for bladder cancer. Urol Oncol. 2013;31:871-7.

22. Hemal AK, Kolla SB, Wadhwa P, Dogra PN, Gupta NP. Laparoscopic radical cystectomy and extracorporeal urinary diversion: a single center experience of 48 cases with three years of follow-up. Urology. 2008;71:41-6.

23. Parekh DJ, Messer J, Fitzgerald J, Ercole B, Svatek R. Perioperative outcomes and oncologic efficacy from a pilot prospective randomized clinical trial of open versus robotic assisted radical cystectomy. J Urol. 2013;189:474-9

24. Albisinni S, Rassweiler J, Abbou CC, Cathelineau X, Chlosta P, Fossion L, et al. Long-term analysis of oncological outcomes after laparoscopic radical cystectomy in Europe: results from a multicentre study by the European Association of Urology (EAU) section of Uro-technology. BJU Int. 2015;115:937-45.

25. Albisinni S, Limani K, Ingels L, Kwizera F, Bollens R, Hawaux E, et al. Longterm evaluation of oncologic and functional outcomes after laparoscopic open-assisted radical cystectomy: a matched-pair analysis. World J Urol. 2014;32:1455-61.

26. Springer C, Mohammed N, Alba S, Theil G, Altieri VM, Fornara P, et al. Laparoscopic radical cystectomy with extracorporeal ileal neobladder for muscle-invasive urothelial carcinoma of the bladder: technique and shortterm outcomes. World J Urol. 2014;32:407-12.

27. Nunez-Mora C, Garcia MJ, Cabrera-Castillo PM, Garcia-Tello A, Gonzalez J, Angulo JC. Feasibility of lymphadenectomy in laparoscopic radical cystectomy. Urology. 2010;76:759-63.

28. Herr H, Lee C, Chang S, Lerner S. Standardization of radical cystectomy and pelvic lymph node dissection for bladder cancer: a collaborative group report. J Urol. 2004;171:1823-8. 1827-8

29. Stein JP, Penson DF, Cai J, Miranda G, Skinner EC, Dunn MA, et al. Radical cystectomy with extended lymphadenectomy: evaluating separate package 
versus en bloc submission for node positive bladder cancer. J Urol. 2007; 177:876-81. discussion 881-2

30. Tang K, Li H, Xia D, Hu Z, Zhuang Q, Liu J, et al. Laparoscopic versus open radical cystectomy in bladder cancer: a systematic review and meta-analysis of comparative studies. PLoS One. 2014;9:e95667.

31. Chade DC, Laudone VP, Bochner BH, Parra RO. Oncological outcomes after radical cystectomy for bladder cancer: open versus minimally invasive approaches. J Urol. 2010;183:862-9.

32. Dotan ZA, Kavanagh K, Yossepowitch O, Kaag M, Olgac S, Donat M, et al. Positive surgical margins in soft tissue following radical cystectomy for bladder cancer and cancer specific survival. J Urol. 2007;178:2308-12. 2313

33. Moschini M, Karnes RJ, Sharma V, Gandaglia G, Fossati N, Dell'Oglio P, et al. Patterns and prognostic significance of clinical recurrences after radical cystectomy for bladder cancer: a 20-year single center experience. Eur J Surg Oncol. 2016;42:735-43.

Submit your next manuscript to BioMed Central and we will help you at every step:

- We accept pre-submission inquiries

- Our selector tool helps you to find the most relevant journal

- We provide round the clock customer support

- Convenient online submission

- Thorough peer review

- Inclusion in PubMed and all major indexing services

- Maximum visibility for your research

Submit your manuscript at www.biomedcentral.com/submit
Biomed Central 